\title{
The Lipopolysaccharides of Fruiting and Non-fruiting Myxobacteria
}

\author{
By I. W. SUTHERLAND AND M. L. SMITH \\ Department of Microbiology, University of Edinburgh, Edinburgh, $\mathrm{EH}_{9}{ }_{3} \mathrm{JG}$
}

(Received 9 August 1972)

\begin{abstract}
SUMMARY
Lipopolysaccharides were obtained from a number of strains of yellowpigmented rods identified as Cytophaga species and from representative strains of fruiting myxobacteria. The major monosaccharide components of the lipopolysaccharides were identified by paper chromatography and subsequent analysis. Most preparations contained ribose, mannose and galactose and no major differences were seen between the composition of fruiting and non-fruiting myxobacterial lipopolysaccharides. Other sugars detected included rhamnose, glucose, glucosamine and galactosamine, but some of the polymers may also contain small amounts of other monosaccharides which have not yet been identified. The chemical similarity of the lipopolysaccharides to analogous polymers from other Gram-negative bacteria confirms the belief from cytological studies that the cell wall of myxobacteria resembles that of typical Gram-negative prokaryotes.
\end{abstract}

\section{INTRODUCTION}

The myxobacteria differ from most other groups of bacteria in showing gliding motility on solid surfaces and, at least in some genera, in undergoing various cycles of cell differentiation. Many early reports suggested that the unusual type of motility might be accompanied by differences in the surface of myxobacterial cells from those found in the eubacteria. Various cytological investigations have now refuted this; Pate \& Ordal (1967) observed a layer thought to be mucopeptide together with plasma membrane, peripheral fibrils and an outer membrane in Chondrococcus columnaris. They also detected material at the cell surface stainable with ruthenium red and consequently thought to be an acid polysaccharide. A similar slime was observed in the non-fruiting cultures of Myxobacter species (Stewart \& Brown, 1969). Extensive electron-microscopic examination of another myxobacterial species, Sporocytophaga myxococcoides, led Holt \& Leadbetter (1967) to conclude that vegetative cells showed no significant differences from the anatomy of Gram-negative Eubacteriales.

Most strains of myxobacteria produce variable amounts of slime during laboratory culture and this surface polysaccharide from Cytophaga hutchinsonii contained uronic acid(s) and pentoses (Norman \& Fuller, 1942). Slime from C. hutchinsonii and Sporocytophaga myxococcoides showed that both polymers were anionic heteropolysaccharides (Martin, Preusser \& Verma, I968). The sugars found in both substances were glucose, mannose, arabinose, xylose and glucuronic acid. The slime from the Sporocytophaga strain also contained galactose. In contrast, slime from $C$. columnaris was a homopolysaccharide containing D-galactosamine, $50 \%$ of which was $N$-acetylated (Johnson \& Chilton, 1966). The mucopeptide of Myxococcus xanthus cells and microcysts, comprising about $0.6 \%$ of the dry weight of each, closely resembled the mucopeptide of other Gram-negative bacteria, containing $\mathrm{N}$-acetyl-glucosamine, acetyl muramic acid, glutamic acid, diaminopimelic acid and alanine in the ratio $0 \cdot 75,0 \cdot 75, \mathrm{I}, \mathrm{I}, \mathrm{I} \cdot 7$ (White, Dworkin \& Tipper, I968). The same type 
of mucopeptide was present in C. hutchinsonii walls (Verma \& Martin, 1967). If they conform to the same pattern of cell wall polymers as other Gram-negative bacteria, myxobacteria should also contain lipopolysaccharides. Information on these is scanty, but a recent report on the lipopolysaccharide composition of a strain of Myxococcus fulvus (Weckesser, Mayer $\&$ Drews, I97I) disclosed the presence of 3-O-methyl-D-xylose. The optical enantiomorph of this unusual methyl pentose was discovered simultaneously in the budding bacterium Rhodopseudomonas viridis, but whether these unusual sugars are of widespread occurrence is still uncertain.

The object of the present study was to compare the phenol-extractable polysaccharides of a number of Cytophaga strains with the corresponding polymers from representative species of fruiting myxobacteria and to determine the similarity or otherwise of the polymers isolated to corresponding material from eubacteria.

\section{METHODS}

Bacterial strains and methods of culture. The strains used in this study, together with their sources, are listed in Table I. The Cytophaga strains were mainly isolated in our laboratory and showed the following characteristics (cf. Mitchell, Hendrie \& Shewan, 1969): Gramnegative rods; mainly long and slightly filamentous, showing gliding motility on solid surfaces; no resting cells or fruiting bodies detectable; slime frequently present (see Table I); yellow-pigmented, spreading colonies growing optimally at 30 to $32{ }^{\circ} \mathrm{C}$; lysis of heated bacterial cells observed on bacterial-cell agar plates; gelatin liquefied and 'Azocoll' (Calbiochem-coloured protein conjugate) hydrolysed; $O$-nitrophenyl $\beta$-D-galactoside and $O$-nitrophenyl $\beta$-D-glucosaminide hydrolysed. All strains grew on a simple synthetic medium in which the carbon source was $I \%$ (w/v) sodium glutamate. The Cytophaga strain 292 of marine origin grew equally well on a similar synthetic medium with a sea-water salts base. The Cytophaga auarantiaca and Sporocytophaga myxococcoides strains grew slowly on the glutamate synthetic medium with cellulose added either as a suspension or in the form of sheets of Whatman no. I paper.

Cells for preparation of polysaccharides were grown in 11 samples of the appropriate medium in 2-1 Erlenmeyer flasks shaken at $200 \mathrm{rev} . / \mathrm{min}$ at $30^{\circ} \mathrm{C}$ on an orbital shaker (L.H. Engineering, Stoke Poges, Buckinghamshire). Cellulolytic bacteria were harvested after 7 days of incubation and other strains of non-fruiting myxobacteria after 2 to 3 days. The representative strains of higher myxobacteria were grown similarly for 4 to 5 days in shaken flasks of $\mathrm{C} /$ Io medium (Rechenbach \& Dworkin, 1969). All bacteria were gently washed with $0.9 \%(\mathrm{w} / \mathrm{v})$ saline and then lyophilized. The cellulolytic strains were harvested as a cell pellet with residual cellulose and the entire pellet was lyophilized.

Lipopolysaccharide and polysaccharide preparation. Extraction of bacteria with $45 \%$ $(\mathrm{w} / \mathrm{v})$ aqueous phenol was by the method of Lüderitz et al. (1965), followed by ultracentrifugation at $100000 \mathrm{~g}$ for 3 to $4 \mathrm{~h}$ to yield a deposit of the lipopolysaccharide gel (LPS) and a supernatant solution (SF) containing soluble polysaccharides. For cellulolytic strains the cellulose was removed by filtration from the dialysed phenol extracts. No appreciable cellulose-derived material was found in the subsequent extracts. Lipid-free polysaccharides (PS) were prepared from LPS by hydrolysis in $\mathrm{I} \%(\mathrm{v} / \mathrm{v})$ acetic acid for $\mathrm{I} h$ at $100{ }^{\circ} \mathrm{C}$. Degraded material of low molecular weight was removed by dialysis and precipitated lipid was deposited by low-speed centrifugation. All polysaccharide and lipopolysaccharide preparations were lyophilized.

Analytical methods. Total hexose, heptose and methyl pentose estimations were performed 
Table I. Strains of myxobacteria and yields of polysaccharides (as \% dry weight)

C. aurantiaca

\begin{tabular}{|c|c|c|c|c|c|}
\hline Designation & Strain & Source & $\begin{array}{c}\text { LPS } \dagger \\
(\%)\end{array}$ & $\begin{array}{l}\mathrm{SF} \dagger \\
(\%)\end{array}$ & $\begin{array}{l}\text { Mucoid } \\
\text { character }\end{array}$ \\
\hline \multirow[t]{17}{*}{ Cytophaga } & NCIB 9336 & - & 0.7 & $3 \cdot 3$ & + \\
\hline & NCIB 9337 & - & $I \cdot I$ & $2 \cdot 9$ & + \\
\hline & GI & Soil & $2 \cdot 2$ & $6 \cdot 6$ & ++ \\
\hline & $\mathrm{G} 2$ & Soil & 0.9 & 0.9 & \pm \\
\hline & G3 & Soil & $I \cdot 9$ & $5 \cdot I$ & \pm \\
\hline & G4 & Soil & $2 \cdot 2$ & $5 \cdot 2$ & \pm \\
\hline & G5 & Soil & $3 \cdot 0$ & $5 \cdot 9$ & ++ \\
\hline & G6 & Soil & $1 \cdot 8$ & $2 \cdot 7$ & + \\
\hline & G7 & Soil & $2 \cdot 5$ & $3 \cdot 8$ & \pm \\
\hline & G8 & Soil & $\mathrm{I} \cdot 7$ & $4 \cdot 2$ & \pm \\
\hline & C3 & Lake water & $2 \cdot 4$ & $3 \cdot 9$ & ++ \\
\hline & $\mathrm{C} 4$ & Lake water & $3 \cdot 4$ & $3 \cdot 7$ & ++ \\
\hline & c6 & Lake water & 0.7 & $I \cdot 9$ & ++ \\
\hline & $\mathrm{C7}$ & Lake water & 0.4 & $I \cdot 7$ & 一 \\
\hline & $\mathrm{H} 2$ & Soil & $I \cdot I$ & $2 \cdot 6$ & ++ \\
\hline & $\mathrm{H}_{3}$ & Soil & $1 \cdot I$ & $\mathrm{I} \cdot 9$ & ++ \\
\hline & NCMB 292 & Sea-water & 0.7 & $4 \cdot 4$ & ++ \\
\hline C. aurantiaca & NCIB 8628 & - & - & - & - \\
\hline Sporocytophaga myxococcoides & NCIB 8639 & - & 一 & - & - \\
\hline S. cauliformis & NCIB 9487 & - & - & - & - \\
\hline Myxococcus xanthus & - & Department strain & $0 \cdot 7$ & $\mathrm{I} \cdot 8$ & \pm \\
\hline M. virescens & MXVI & (Dr Reichenbach) & $\mathrm{I} \cdot 8$ & $4 \cdot 3$ & \pm \\
\hline Chondrococcus exiguus & $\operatorname{ccc} 4$ & (Dr Reichenbach) & $1 \cdot 4$ & $3 \cdot 8$ & \pm \\
\hline Stigmatella aurantiaca & sga I & (Dr Reichenbach) & 0.5 & $I \cdot 0$ & 一 \\
\hline Polyangium ferrugineum & $\mathrm{PBr}$ & (Dr Reichenbach) & $1 \cdot 5$ & $2 \cdot 9$ & - \\
\hline P. fuscum & - & (Dr Kuhlwein) & 0.3 & $1 \cdot 3$ & - \\
\hline Sorangium compositum & SocI & Rabbit dung $\ddagger$ & 0.4 & $I \cdot 2$ & - \\
\hline
\end{tabular}

on unhydrolysed material by micro-modifications of the cysteine-sulphuric acid reaction under appropriate conditions (Dische \& Shettles, I948; Dische, Shettles \& Osnos, I949). Pentose was assayed by the orcinol technique. D-Glucose and D-galactose were determined,

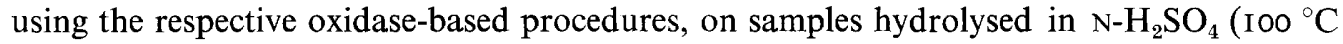
for $4 \mathrm{~h}$ ) and neutralized with Amberlite resin IR $4 \mathrm{IO}\left(\mathrm{HCO}_{3}\right.$ form). Total hexosamine was determined on hydrolysates $\left(6 \mathrm{~N}-\mathrm{HCl}\right.$ at $100{ }^{\circ} \mathrm{C}$ for $\left.6 \mathrm{~h}\right)$ after evaporation of the acid in vacuo; D-galactosamine was assayed specifically in the hydrolysates with the galactose oxidase reagent. Hydrolysates $\left(\mathrm{H}_{2} \mathrm{SO}_{4}\right.$ or $\left.\mathrm{HCl}\right)$ were examined by paper chromatography for the presence of monosaccharides. The solvents were: I, pyridine-butan-I-ol-water $(4: 6: 3$, by vol.) (Whistler \& Conrad, 1954); and II, butan-I-ol-acetic acid-water ( $4: 1: 5$, by vol.) (Partridge, 1946). Sugars were detected with saturated aniline oxalate solution or alkaline silver nitrate and amino sugars with ninhydrin reagent. 


\section{RESULTS}

Isolation of lipopolysaccharides. The phenol extraction procedure, widely used to obtain lipopolysaccharides from whole cells of Gram-negative bacteria, has also proved successful for the family Myxobacteriacea. Low yields were at first obtained from the fruiting species; this was due to the difficulty of suspending the cells in water and was overcome by a brief extraction with chloroform/methanol (2: I, v/vat) room temperature prior to phenol extraction. Purification by ultracentrifugation yielded clear colourless gels of LPS and clear supernatant fluids which, in some preparations, were very viscous. Although the high viscosity was partly due to the presence of RNA, it may also result from surface polysaccharide slime or capsule. The yields of LPS and non-sedimentable material resembled those described for other Gramnegative bacteria (Table I). Because of the presence of cellulose in the material used for extraction, no realistic yields can be given for Cytophaga aurantiaca or Sporocytophaga myxococcoides.

Lipopolysaccharide composition. Preliminary examination of polysaccharide hydrolysates by paper chromatography indicated the presence of a range of monosaccharide components of which the most frequent were ribose, mannose and galactose. Rhamnose was the only 6-deoxyhexose identified and ribose the most frequent pentose. Glucosamine and galactosamine were also detected. The same sugars were observed in hydrolysates of the supernatant fluids after ultracentrifugation (SF), probably due to material of LPS origin but lower molecular weight failing to sediment in the ultracentrifuge. Subsequently, all the LPS preparations were analysed for the sugars identified in paper chromatograms (Table 2). Traces of other sugars were found in several preparations; as judged by their intensity of staining on chromatograms, the amount of these other monosaccharides probably represented less than $5 \%$ of the total sugars present and was seldom enough to permit characterization. All the lipopolysaccharides contained material giving a positive reaction in the thiobarbituric acid test as modified by Heath (Lüderitz et al. 1965), but the lack of satisfactory standards prevented quantitative estimation of the presumed 2-keto-3-deoxyoctonate. More surprising was the observed content of heptose as assayed by the cysteine-sulphuric acid test. All lipopolysaccharides were so tested but the range of values obtained was o to $2 \%$. This may indicate a lack of heptose or, alternatively, much smaller quantities than are commonly found in the lipopolysaccharides of the eubacteria.

Many of the chromatograms of lipopolysaccharide hydrolysates carried a spot staining with alkaline silver nitrate and having $R_{\mathrm{glc}} 2 \cdot 0$ and $R_{\mathrm{rhamnose}} \mathrm{I} \cdot 2$ in solvent I. The $R_{\mathrm{glc}}$ and $R_{\text {rhamnose }}$ in solvent II were $3 \cdot 4$ and I.3 respectively. This is similar to the mobility of $3-O$ methyl-D-xylose (Weckesser et al. 1971) and the unknown substance also resembled this methylpentose in reacting with aniline oxalate to yield a red-coloured product. A small amount of the sugar was purified by preparative paper chromatography in solvent I. It did not react in either the orcinol test for pentoses or the cysteine-sulphuric reaction for 5methylpentoses. Consequently, the presence of the 3-O-methylpentose does not affect the values obtained in the analyses for 5-methylpentoses and pentoses.

Hydrolysates of several lipopolysaccharides prepared from fruiting myxobacteria (but not from the Cytophaga strains tested) contained both ribose and another substance staining red with aniline oxalate. From its position on chromatograms run in both solvent systems, the pentose was identified as xylose; as judged by the intensity of staining of LPS hydrolysates, the ratio of xylose (when present) to ribose was about $1: 5$, except in Chondrococcus LPS which contained xylose but little ribose. Weakly stained spots were observed on some 
Table 2. Composition of myxobacterial lipopolysaccharides (as \% dry weight)

\begin{tabular}{|c|c|c|c|c|c|c|c|}
\hline Strain & Rhamnose & Ribose & Mannose & Glucose & Galactose & $\begin{array}{l}\text { Hexo- } \\
\text { samine }\end{array}$ & $\begin{array}{l}\text { Galactc } \\
\text { samine }\end{array}$ \\
\hline \multicolumn{8}{|l|}{ Cytophaga } \\
\hline 9336 & $6 \cdot 7$ & 10.6 & $10 \cdot 5$ & $I \cdot 6$ & $I \cdot 2$ & $5 \cdot 6$ & 0 \\
\hline 9337 & 0 & $10 \cdot 4$ & $8 \cdot 3$ & 0 & $2 \cdot 7$ & I $3 \cdot 2$ & $6 \cdot 6$ \\
\hline GI & 0 & I $2 \cdot 8$ & II 0 & 0.7 & $5 \cdot 3$ & $13 \cdot 2$ & $5 \cdot 7$ \\
\hline G2 & 0 & 13.5 & II 3 & $9 \cdot 6$ & 0.6 & $6 \cdot 5$ & 0 \\
\hline G3 & 0 & $12 \cdot 5$ & $10 \cdot 0$ & o & $1 \cdot 0$ & $7 \cdot 3$ & 0 \\
\hline G4 & $8 \cdot 2$ & $7 \cdot 4$ & $7 \cdot 2$ & $0 \cdot 7$ & $5 \cdot 6$ & $9 \cdot 6$ & 0 \\
\hline G5 & $4 \cdot 9$ & $7 \cdot 1$ & $8 \cdot I$ & $4 \cdot 0$ & $4 \cdot 7$ & II 9 & $3 \cdot 4$ \\
\hline G6 & $11 \cdot 2$ & 10.7 & $9 \cdot 0$ & $1 \cdot 2$ & $7 \cdot 0$ & $7 \cdot 2$ & 0 \\
\hline G7 & $8 \cdot 4$ & $9 \cdot 3$ & $5 \cdot 6$ & $9 \cdot 2$ & 0.7 & $1 \mathrm{I} \cdot 2$ & $7 \cdot 8$ \\
\hline G8 & 0 & $13 \cdot 2$ & $8 \cdot 0$ & $I \cdot 4$ & $8 \cdot 3$ & $7 \cdot 7$ & 0 \\
\hline $\mathrm{C} 3$ & 0 & $9 \cdot 3$ & 10.2 & 0.6 & 0.5 & $10 \cdot 1$ & 5.0 \\
\hline $\mathrm{C} 4$ & 0 & $12 \cdot 9$ & $9 \cdot 0$ & $I \cdot I$ & $6 \cdot 5$ & II $\cdot 4$ & $4 \cdot 4$ \\
\hline c6 & 0 & $14 \cdot 4$ & $8 \cdot 7$ & $I \cdot 6$ & $4 \cdot 8$ & 13.9 & 5.9 \\
\hline C7 & 0 & I I 0 & $6 \cdot 2$ & $1 \cdot 6$ & $4 \cdot 7$ & $9 \cdot 6$ & $4 \cdot 0$ \\
\hline $\mathrm{H} 2$ & $6 \cdot 8$ & $7 \cdot 7$ & $9 \cdot 3$ & I I 5 & $9 \cdot 3$ & II 6 & $3 \cdot 9$ \\
\hline H3 & 0 & $10 \cdot 2$ & $13 \cdot 0$ & $3 \cdot 8$ & $6 \cdot 7$ & $10 \cdot 8$ & $3 \cdot 8$ \\
\hline 292 & 0 & $10 \cdot 5$ & $7 \cdot 2$ & $3 \cdot 3$ & $6 \cdot 6$ & $9 \cdot 8$ & $3 \cdot 8$ \\
\hline C. aurantiaca & I I $\cdot 6$ & $9^{\cdot} \mathrm{I}$ & $10 \cdot 5$ & $7 \cdot 5$ & 0 & $7 \cdot 5$ & o \\
\hline Sporocytophaga myxococcoides & 0 & $11 \cdot 4$ & $5 \cdot 7$ & $7 \cdot 3$ & $7 \cdot 2$ & $6 \cdot 8$ & 0 \\
\hline S. cauliformis & 0 & 13.4 & $8 \cdot 5$ & $2 \cdot 5$ & 13.4 & $5 \cdot 2$ & 0 \\
\hline Myxococcus xanthus & $8 \cdot 6$ & $15 \cdot 2$ & 0 & $7 \cdot 9$ & $5 \cdot 1$ & $15 \cdot 6$ & $5 \cdot 6$ \\
\hline$M$. virescens & 0 & $10 \cdot 7$ & $9 \cdot 3$ & $6 \cdot 4$ & 0 & $I I \cdot I$ & $6 \cdot 4$ \\
\hline Chondrococcus exiguus & $14 \cdot 1$ & $12 \cdot 4$ & $11 \cdot 0$ & $4 \cdot 4$ & $6 \cdot 6$ & $7 \cdot 6$ & $3 \cdot 8$ \\
\hline Stigmatella aurantiaca & I $2 \cdot 5$ & $7 \cdot 4$ & I $8 \cdot 5$ & $5 \cdot 0$ & $2 \cdot 4$ & $5 \cdot 0$ & 0 \\
\hline Polyangium ferrugineum & $6 \cdot 7$ & $9 \cdot 7$ & $9 \cdot 0$ & $7 \cdot 2$ & $2 \cdot 9$ & $7 \cdot 2$ & 0 \\
\hline P. fuscum & $7 \cdot 5$ & 110 & $9 \cdot 0$ & I $2 \cdot 4$ & $1 \cdot 0$ & $6 \cdot 0$ & 0 \\
\hline Sorangium compositum & 0 & 13.4 & $I \cdot 4$ & $5 \cdot 2$ & $4 \cdot 0$ & $7 \cdot 7$ & $3 \cdot 6$ \\
\hline
\end{tabular}

chromatograms developed with ninhydrin but insufficient material was available for further identification or characterization of the possible amino sugars.

Derivation of sugars found in lipopolysaccharide hydrolysates. Even after purification of lipopolysaccharide solutions by ultracentrifugation, preparations from whole cells can be associated with contaminating polymers; these may include nucleic acids and exopolysaccharides. If the ribose were derived from RNA rather than lipopolysaccharide, solutions should have an appreciable extinction at $260 \mathrm{~nm}$. No such absorption was demonstrated by solutions of lipopolysaccharides, although the supernatants obtained after ultracentrifugation were rich in nucleic acids as judged by their extinction at $260 \mathrm{~nm}$ and the high ribose content. Further proof that the ribose in myxobacterial preparations was an integral component of the LPS was obtained by an examination of LPS prepared from cell walls of representative Cytophaga strains. It closely resembled the product from whole cells both in its ribose content and in the other sugars present.

The lipid A component of eubacterial lipopolysaccharides contains D-glucosamine; consequently, glucosamine is found in most lipopolysaccharides although it may not necessarily be part of the polysaccharide (Lüderitz, Staub \& Westphal, 1966). Mild hydrolysis with acetic acid ( $\mathrm{I} \%, \mathrm{v} / \mathrm{v}$, at $100{ }^{\circ} \mathrm{C}$ for $\left.\mathrm{I} h\right)$ splits off the lipid $\mathrm{A}$, leaving a lipid-free watersoluble polysaccharide. Where sufficient material was available, Cytophaga lipopolysaccharides were freed from lipid A by acetic acid hydrolysis, dialysed, centrifuged and the supernatant polysaccharide solution lyophilized. Analysis of the lipid-free polysaccharides was 
Table 3. Composition of Cytophaga lipid-free polysaccharides (as \% dry weight)

\begin{tabular}{|c|c|c|c|c|c|c|c|}
\hline Strain & Rhamnose & Ribose & Manose & Glucose & Galactose & Hexosamine & $\begin{array}{c}\text { Galacto } \\
\text { amine }\end{array}$ \\
\hline GI & 一 & 15.0 & - & 一 & - & 一 & - \\
\hline G4 & $I I \cdot I$ & $15 \cdot 1$ & 14.5 & 0 & $16 \cdot 4$ & $14 \cdot 2$ & 0 \\
\hline G5 & 0 & 10.7 & $18 \cdot 0$ & $14 \cdot 3$ & 6.5 & $16 \cdot 4$ & 5.9 \\
\hline G6 & $16 \cdot 8$ & $10 \cdot 7$ & $23 \cdot 8$ & $I \cdot 7$ & $18 \cdot 8$ & $13 \cdot I$ & 0 \\
\hline G7 & I6-7 & $12 \cdot 6$ & $14 \cdot 2$ & $9 \cdot 2$ & $16 \cdot 6$ & $17 \cdot 7$ & 10.3 \\
\hline G8 & $12 \cdot 4$ & $24 \cdot 8$ & $14 \cdot 9$ & 0.8 & I $2 \cdot 3$ & I $2 \cdot 0$ & 0 \\
\hline C3 & 0 & $19 \cdot 3$ & $21 \cdot 3$ & 0 & $5 \cdot 7$ & $13 \cdot 0$ & $6 \cdot 5$ \\
\hline $\mathrm{C} 4$ & 0 & 15.0 & 18.0 & 0 & $18 \cdot 8$ & $17 \cdot 0$ & $8 \cdot 1$ \\
\hline c6 & 0 & I $4 \cdot 3$ & $22 \cdot 5$ & 0 & $14 \cdot 8$ & I 5.9 & $5 \cdot I$ \\
\hline 9336 & $16 \cdot 7$ & $15 \cdot 0$ & $14 \cdot 5$ & 0.6 & $3 \cdot 5$ & $7 \cdot \mathrm{I}$ & 0 \\
\hline 9337 & 0 & 13.8 & $21 \cdot 8$ & 0.7 & $3 \cdot 8$ & $16 \cdot 4$ & $5 \cdot 4$ \\
\hline
\end{tabular}

performed (Table 3). All contained glucosamine and six of the ten strains tested also contained galactosamine. The other sugars detected were the same as in the LPS preparation. In the Cytophaga lipopolysaccharides, glucosamine thus forms an integral part of the polysaccharide as well as probably forming part of the lipid A.

\section{DISCUSSION}

From all the strains of myxobacteria examined in the present study it proved possible to isolate lipopolysaccharide which is apparently analogous to the corresponding polymer found in other Gram-negative bacteria. In those strains producing microcysts or other differentiated cell forms, the analyses presented here represent a total of the material from vegetative cells and cyst forms, no attempt having been made to separate the two. In Myxococcus xanthus the mucopeptide of cysts and vegetative cells is of quantitatively similar composition (White et al. 1968), but without separation and analysis of the microcysts it is not clear whether they actually contain lipopolysaccharide. The presence of lipopolysaccharide in the vegetative cells of myxobacteria confirms the view derived from cytological studies (e.g. Pate \& Ordal, 1967) that the cell walls of myxobacteria and eubacteria are not grossly different. The amounts of lipopolysaccharide extracted from myxobacteria vary but are again comparable to yields from such groups of bacteria as the Enterobacteriaceae.

The chemical composition of the myxobacterial lipopolysaccharides differs from that of eubacterial lipopolysaccharides only in the actual sugars observed. Many strains possessed a polymer containing ribose, mannose and galactose along with one or both of the hexosamines glucosamine and galactosamine; other monosaccharides found in a number of preparations included glucose and rhamnose. Unlike most eubacterial lipopolysaccharides, heptose was either absent or present in very small amounts in myxobacterial material. Few earlier reports exist on the composition of myxobacterial wall polysaccharides. Mason \& Powelson (1958) detected galactose, glucose, hexosamine and rhamnose in walls of a strain of Myxococcus xanthus and this is consistent with the results currently presented. The extracellular slimes from Cytophaga hutchinsonii and Sporocytophaga myxococcoides were acid heteropolysaccharides which contained several of the sugars found in the lipopolysaccharides (Verma \& Martin, 1967); as there were no checks on the purity of the preparations or on the specificity of the method of extraction used, some of the sugars found might have originated in lipopolysaccharide. No uronic acids were found during the present study, so the presence 
of slime in the polymers used for analysis is unlikely. Lipopolysaccharides from certain groups of bacteria are characterized by the presence of some 'exotic' sugars. Thus, 3,6dideoxyhexoses are widely found in the Enterobacteriaceae and the Parvobacteriaceae (Lüderitz, Jann \& Wheat, I968). The presence of 3-methylxylose in Myxococcus fulvus was recently noted (Weckesser et al. 1971) and this or similar sugars have been found in several of the lipopolysaccharides from myxobacteria, although only in the Chondrococcus exiquus strain were the amounts of methylxylose comparable to those of other component sugars. This type of sugar also occurs in Rhodopseudomonas viridis (Weckesser et al. 1971) while 3,5-dimethylpentoses are known to occur in another photosynthetic species, Rhodopseudomonas capsulata (Weckesser, Mayer \& Drews, 1970).

One surprising aspect of the results was the lack of appreciable differences between lipopolysaccharides prepared from the non-fruiting Cytophaga and Sporocytophaga strains, and the fruiting myxobacteria. Although all these bacteria are currently grouped in the myxobacteria, wide differences are found between the two major groups. The non-fruiting group have $\% \mathrm{GC}$ varying from about 32 to 39 , while the fruiting types form a more compact group within the range 67 to 70 (Mitchell et al. 1969). Considerable differences in the gross composition of the cell wall polysaccharides of the two groups might thus have been expected expected but none were found. The actual polysaccharide structures may still, however, differ. It should prove interesting to determine whether the lipopolysaccharide and its composition remain contant in the fruiting species, or whether, as in more complex microorganisms, different cell wall polymers are formed during different phases of growth.

The support of the Agricultural Research Council is gratefully acknowledged and the authors thank Dr Reichenbach and Dr Kuhlwein for the generous gift of strains and details of their culture.

\section{REFERENCES}

Dische, Z. \& Shettles, L. B. (1948). A specific colour reaction of methylpentoses and a spectrophotometric micromethod for their determination. Journal of Biological Chemistry 175, 595-596.

Dische, Z., Shettles, L. B. \& OsNos, M. (I949). New specific colour reactions of hexoses and spectrophotometric micromethods for their determination. Archives of Biochemistry and Biophysics 22, I $69-186$.

Holt, S. C. \& LeAdbetTer, E. R. (I967). Fine structure of Sporocytophaga myxococcoides. Archiv für Mikrobiologie 57, I99-2 I3.

Johnson, J. L.\& Chilton, W. S. (I966). Galactosamine glycan of Chondrococcus columnaris. Science, New York 152, I $247^{-1} 248$.

LüDERITZ, O., JANN, K. \& WhEAT, R. (I968). Somatic and capsular antigens of gram negative bacteria. In Comprehensive Biochemistry, vol. 26A, pp. 105-228. Edited by M. Florkin and E. M. Stotz. Amsterdam: Elsevier Publishing Company.

Lüderitz, O., Risse, H. J., Schulte-Holthausen, H., Strominger, J. L., Sutherland, I. W. \& Westphal, O. (1965). Biochemical studies of the smooth-rough mutation in Salmonella minnesota. Journal of Bacteriology 89, 343-354.

Lüderitz, O., Staub, A. M. \& WestPhal, O. (I966). Immunochemistry of O and R antigens of Salmonella and related Enterobacteriaceae. Bacteriological Reviews 30, 192-255.

Martin, H. H., Preusser, H. J. \& Verma, J. P. (1968). Über die Oberflächenstruktur von Myxobakterien. II. Anionische Heteropolysaccharide als Baustoffe der Schleimhülle von Cytophaga hutchinsonii and Sporocytophaga myxococcoides. Archiv fïr Mikrobiologie 62, 72-84.

Mason, D. J. \& Powelson, D. (1958). The cell wall of Myxococcus xanthus. Biochimica et biophysica acta 29 , $\mathrm{I}-7$.

Mitchell, T. G., Hendrie, M. S. \& Shewan, J. M. (I969). The taxonomy, differentiation and identification of Cytophaga species. Journal of Applied Bacteriology 32, 40-50.

Norman, W. H. \& Fuller, A. G. (1942). Characteristics of some soil Cytophagas. Journal of Bacteriology $45,564-572$. 
PARTRIDGe, S. M. (1946). Application of the paper partition chromatogram to the qualitative analysis of

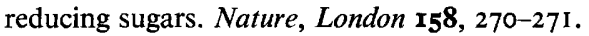

PATE, J. L. \& ORDAL, E. J. (I967). The fine structure of Chondrococcus columnaris. III. The surface layers of Chondrococcus columnaris. Journal of Cell Biology 35, 37-5I.

ReICHENBACH, H. (1970). Nannocystis exedens, a new Myxobacterium of the family Sarangiaceae. Archiv fïr Mikrobiologie 70, I19-138.

Reichenbach, H. \& Dworkin, M. (1969). Studies on Stigmatella aurantiaca (Myxobacteriales). Journal of General Microbiology 58, 3-14.

Stewart, J. R. \& Brown, R. M. (1969). Cytophaga that kills or lyses algae. Science, New York 164, I 523I 524 .

Verma, J. P. \& Martin, H. H. (1967). Chemistry and ultrastructure of surface layers in primitive Myxobacteria: Cytophaga hutchinsonii and Sporocytophaga myxococcoides. Folia microbiologica 12, $248-253$.

WeCKesser, J., MAYER, H. \& Drews, G. (I 970). The identification of 3-O-methyl-L-rhamnose (L-acofriose) as a constituent of the lipopolysaccharides of Myxococcus fulvus and Rhodopseudomonas viridis respectively. European Journal of Biochemistry 16, 153-163.

Weckesser, J., Rosenfelder, G., Mayer, H. \& Drüderitz, O. (I97I). The identification of 3-O-methylD-xylose and 3-O-methyl-L-xylose as constituents of the lipopolysaccharides of Myxococcus fulvus and Rhodopseudomonas viridis respectively. European Journal of Biochemistry 24, II 2-I I 5.

Whistler, R. L. \& ConraD, H. E. (I954). 2-O-(D-Galactopyranosyluronic acid)-L-rhamnose from okra mucilage. Journal of the American Chemical Society 76, 3544-3546.

White, D., Dworkin, M. \& TiPper, D. J. (1968). Peptidoglycan of Myxococcus xanthus: structure and relation to morphogenesis. Journal of Bacteriology 95, 2186-2197. 